\title{
Tornei-me o homo faber por excelência
}

Cyro Del Nero ${ }^{1}$

Doutor em Artes Cênicas, professor titular de Cenografia e Indumentária Teatral da Universidade de São Paulo, na Escola de Comunicações e Artes, Departamento de Artes Cênicas.

E-mail: cyrodn@terra.com.br

Nasci na Rua Miller, no Brás, a setenta metros do Teatro Colombo, que se erguia no Largo da Concórdia, em frente à Estação do Norte; de lá partiam os trens para o Rio de Janeiro. Numa casa pequena, casa de porta e janela, havia aquilo que serviu de primeiro signo artístico para minha vida: um piano alemão, preto, do tipo armário. Um maravilhoso Bechstein que, por falta de espaço, dividia comigo um quarto de dormir. Ali ouvi as sonatas de Beethoven, o Hinário Presbiteriano, os corais de Bach e as aulas que minha mãe ministrava. Minha infância girou ao redor do culto protestante e de sua rica liturgia musical. Música como conteúdo e palavra como forma foram, muito cedo, o embasamento de minha formação. Terminados os estudos no Grupo Escolar Eduardo Prado, ingressei no Mackenzie para atender a uma tradição familiar. Confesso certa inadaptação escolar perene a partir desse momento. Entreguei-me completamente à didática do sem-método e à estruturação de uma coluna vertebral do conhecimento na pluralidade de interesses. Aprendia com as pessoas e as circunstâncias.

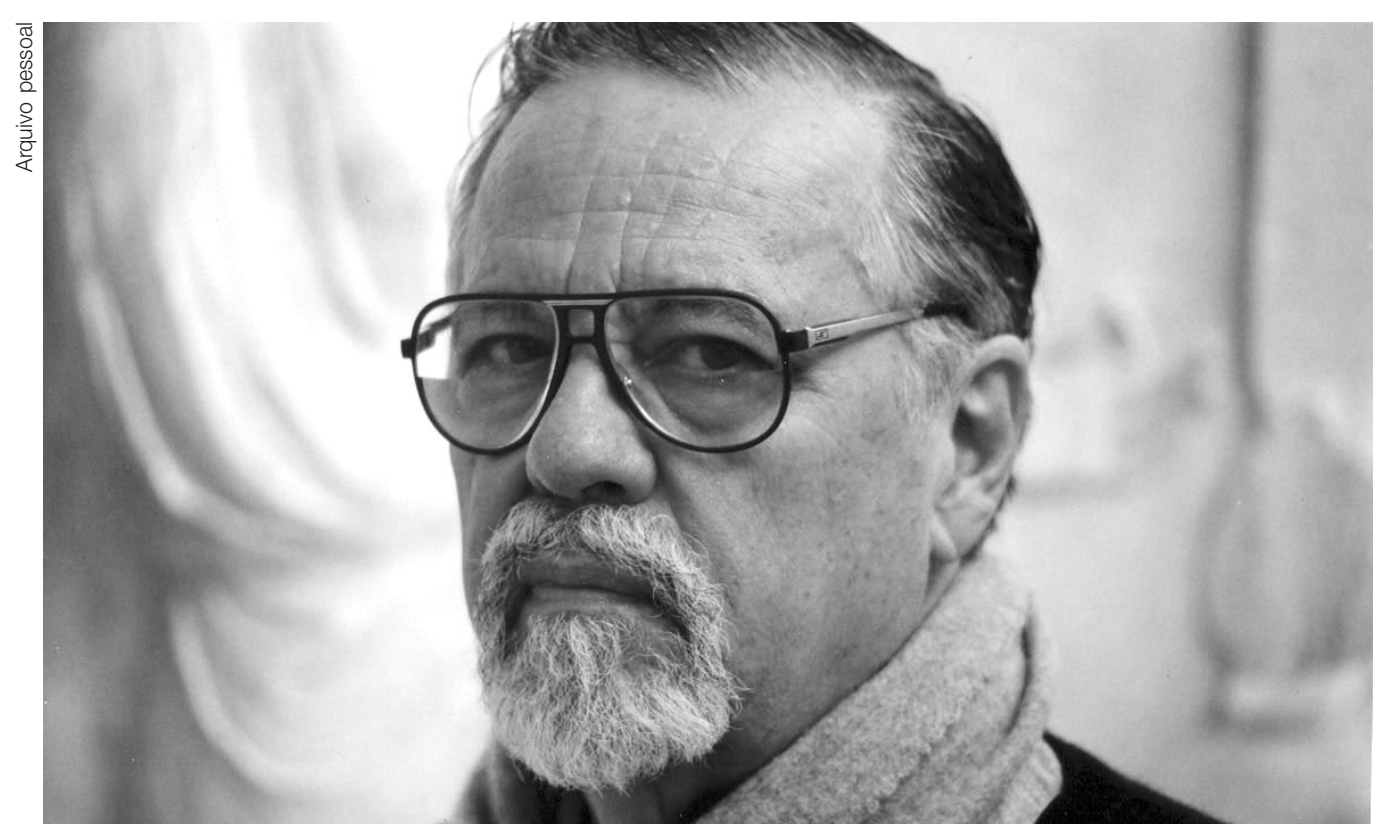

"Para o cenógrafo, todo e qualquer espaço é palco."

1. <http://www.cyrodncenografia.com.br>. 
comunicação \& educação • Ano XII • Número 1 • jan/abr 2007

\section{CULTURA E TEATRO DE UMA GERAÇÃO}

Carregava comigo algo que seria de fundamental importância para minha vida espiritual e intelectual: entusiasmo, sensibilidade pessoal e artística e energia criativa. Era como se um xamã tivesse me habitado e dele eu conservasse a capacidade de expandir ilações litúrgicas e uma constante leitura ritualística do cotidiano. Essa capacidade e essa emoção tornaram-se o embasamento da minha relação com o teatro, porque altar e teatro são os mais antigos gêmeos.

A partir de então, entramos, outros jovens e eu, no perímetro dessa grande afetividade clarividente que foi Mário de Andrade. A soma do que pensávamos podíamos chamar de nosso dia e para este tínhamos uma geografia criada por Mário, a fim de que pensássemos melhor: esse era seu testamento intelectual para nossa formação. Bebemos durante uma década o leite do Mário.

Éramos Manoel Carlos, Antunes Filho, Flávio Rangel, Bento Prado Jr. e muitos outros... Mais tarde, Ruth Escobar, Fernanda Montenegro, Fernando Torres, Carlos Zara... Os adoradores de Minerva. Destes, alguns cursavam regularmente faculdades, mas a maioria era autodidata.

Nos anos 1950, enchi cadernos reproduzindo, copiando, imitando, fazendo variações sobre os desenhos de Picasso: era a única maneira de persegui-lo em vôo. E, então, encontrei a cor nos cenógrafos dos balés russos: Gontcharova e Léon Bakst, que teriam sido mestres coloristas em Bizâncio.

Uma tarde, na Rua Xavier de Toledo, estava caminhando com Manoel Carlos na direção da biblioteca, quando ele me chamou a atenção, olhando para trás.

- Olha! É o Oswald de Andrade.

Quando me voltei, Oswald também se voltou já sorrindo, feliz por ter sido reconhecido. Nos meses seguintes, eu e Manoel Carlos seríamos cabos eleitorais da candidatura de Oswald de Andrade a deputado federal, pelo Partido Republicano Trabalhista, presidido por Guaracy Silveira, com escritórios em frente à biblioteca, na Ladeira Quirino de Andrade.

Quando Carlos Drummond de Andrade publicou Claro enigma, deu-nos o mapa da poesia e o vocabulário da minha geração. Não expressaríamos mais as coisas da mesma maneira.

Nesses mesmos anos 1950, nosso dia tinha três rituais: pela manhã, Discoteca Municipal. À tarde, encontrávamo-nos todos na Biblioteca Municipal Mário de Andrade. Ali nos reuníamos aos pés da estátua de Minerva, adquirentes que éramos de signos e performances intelectuais. Usávamos a biblioteca como os gregos utilizavam as colunas da Stoa para o exercício retórico sobre seus deuses pessoais. À noite, Teatro Municipal. Íamos beber do vinho dionisíaco dos espetáculos de ópera, dança, teatro e música, na década que foi a última e mais rica de ofertas artísticas.

Minha estréia como cenógrafo - direção do Flávio Rangel - aconteceu no final dos anos 1940: Do mundo nada se leva, de Kaufman, Moss \& Hart, no 
Teatro Leopoldo Fróes. Sou de 1931 e tinha, portanto, 18 anos. Foi uma glória! Em seguida, veio o cenário para Plauto, O Anfitrião, para um grupo chamado Novos Comediantes e dirigido por Zizos Charatsaris, diretor grego que estava no Brasil após uma carreira teatral na Macedônia. Desenhei o cenário e os costumes, e foi uma grande festa brincar de teatro clássico.

\section{A FORMAÇÃO NO EXTERIOR}

Em 1956, com apoio de Cicillo Matarazzo, fiz minha primeira viagem para a Grécia. Entrei pelo norte, por Tessalônica, capital da Macedônia, no trem Orient Express, que vinha de Lisboa, onde eu havia desembarcado. Desse momento em diante, a Grécia tornou-se para mim um caso pessoal e a percorro, anualmente, há cinqüenta anos. Tenho a vivência de seu teatro, sua história, sua arte, suas ilhas, suas montanhas, seus sítios arqueológicos.

Em Atenas, tive meu encontro com a essência do teatro, com sua grandeza, com as razões de se fazer teatro, com o pathos teatral, com a relação do edifício teatral e o universo, com a provocação da catarse coletiva, com a presença dos deuses e, sobretudo, com a força transformadora da palavra através de atores.

Como conseqüência desse amor duradouro pela Grécia, fui escolhido, em 1995, representante no Brasil da Fundação para a Cultura Helênica, Atenas. No ano seguinte, tornei-me membro do Conselho Consultivo da Câmara do Comércio e Indústria Brasil-Grécia para assuntos culturais.

Depois da Grécia, veio a Alemanha. No Teatro Estadual de Württemberg, em Stuttgart, batia o ponto às oito horas da manhã numa fila de profissionais cobertos por guarda-pó regulamentar, quase todos senhores de cabelos brancos, respeitáveis desenhistas, pintores, escultores, cenotécnicos, iluminadores. Parecia uma indústria como outras, mas havia uma tradicional eficiência efetiva. Eu era assistente de Frau Leny Bauer-Ecsy, cenógrafa especializada em balés clássicos, como, por exemplo, A Bela Adormecida, Giselle etc. $\mathrm{O}$ fato de saber fazer maquetes garantiu-me enormes oportunidades, inclusive o convívio e o trabalho em Stuttgart com Wieland Wagner, diretor do Festival de Bayreuth, um dos maiores encenadores de ópera de seu tempo.

Viajei o resto da Europa, estive em Londres antes que os Beatles tivessem saído de Liverpool e na National Galery encontrei Nicolas de Stael. Fui ver pintores em Amsterdã: A Ronda da Guarda e Os Noivos de Rembrandt. Atravessei a França entrando pela Alsácia, escarafunchei Paris - Louvre, Vista de Delft, L'Orangerie, Ninféas -, visitei diariamente as galerias da rive gauche, vi as obras da geração dos anos 1950, Soulage, Hartung, Stael, Bissière e muito mais.

Foi ainda em Stuttgart que consegui, durante esses anos, visitando a biblioteca da cidade, metodizar estudos de cenografia e teatro grego, depois de vivenciá-lo; tudo sobre teatro grego e cenografia do teatro francês. Em seguida, de repente, Appia e Gordon Craig, construtivismo russo e expressionismo alemão. 


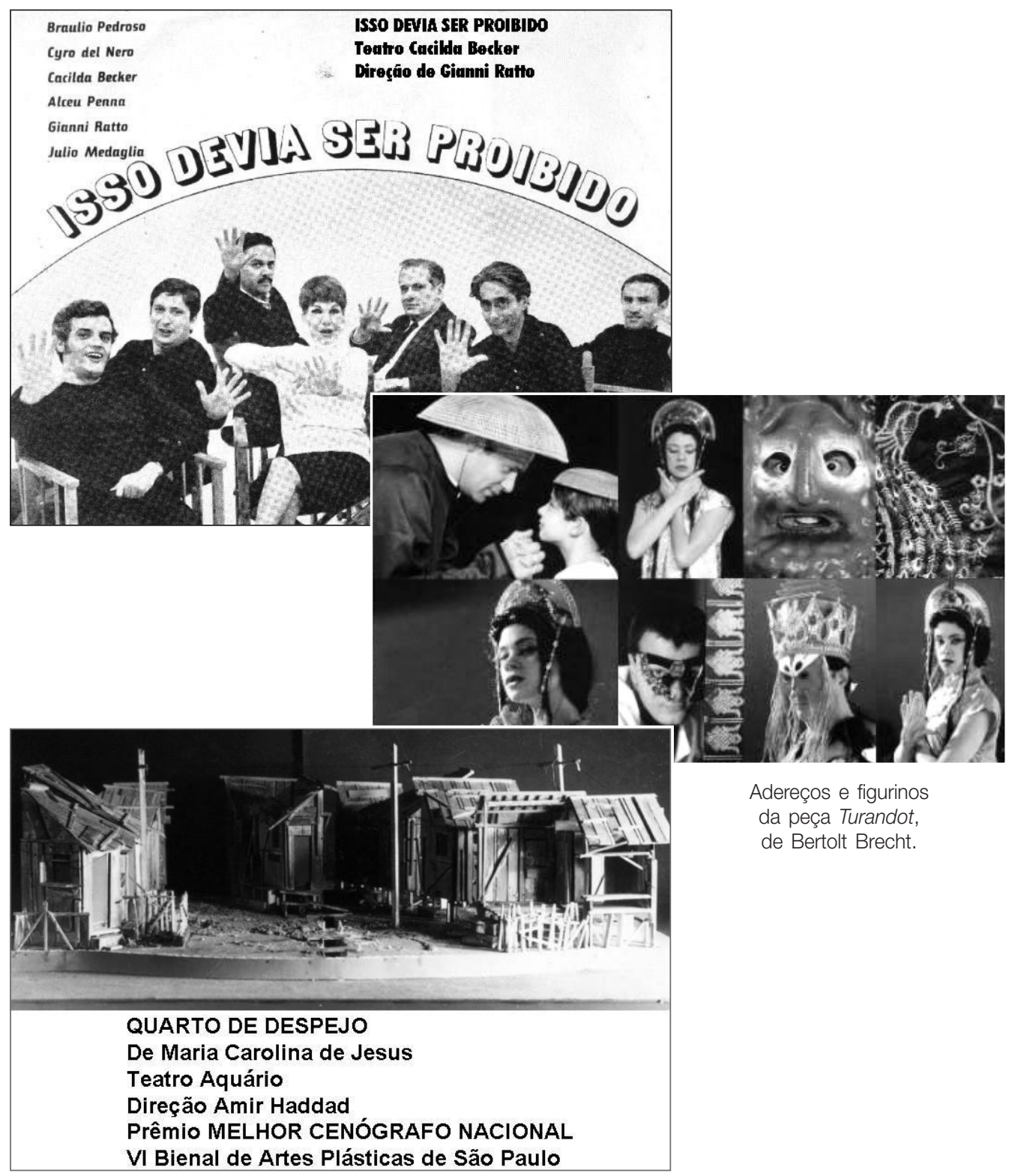

Cenografia teatral: arte exigente, ofício nota 10.

\section{NO BRASIL}

Durante essa estada na Europa, minha geração colocara-se profissionalmente, aprendera a viver. Chegando de lá, fui trabalhar não só no teatro, mas também na televisão, que iniciava sua história no País. Fiz cenografia na TV Record para um programa dirigido por Nilton Travesso e escrito por Manoel Carlos. A TV Excelsior, que seria inaugurada um mês depois, contratou-me como diretor de arte.

No teatro, Flávio Rangel convidou-me para juntos assumirmos a direção e a cenografia do Teatro Brasileiro de Comédia e, com a bênção de Franco 
Zampari, começamos produzindo uma remontagem de Leonor de Mendonça, de Gonçalves Dias, que, anos antes, havia sido dirigida por Adolfo Celi.

Em cinema e TV, produzi cenografia e trabalhei como diretor de arte; criei também programas de comunicação visual. Cenografei eventos, feiras de amostras e fiz cenários e editoriais fotográficos de moda. Ilustrei e elaborei capas de livros, discos e relatórios anuais. Projetei e realizei pavilhões para o governo federal em feiras internacionais. Expus meus trabalhos, ganhei inúmeros prêmios, dei conferências, formei profissionais nas áreas de cenografia, artes gráficas e direção de arte. Dirigi a criação de campanhas promocionais, projetei e instalei áreas de showroom para a indústria e o comércio. Projetei costumes para espetáculos teatrais e shows de moda.

Durante dez anos, fui cenógrafo, diretor de arte e diretor de fotografia para eventos de moda no Brasil. A exigência desse trabalho foi tão grande que tive de me organizar empresarialmente, montando um estúdio fotográfico - depois viria um segundo -, o qual seria o primeiro laboratório de revelação e copiagem de fotos coloridas em São Paulo, para uso exclusivo de um estúdio de fotografia de moda. Três anos mais tarde, organizei um grande departamento de costura, dirigido pelo figurinista Alceu Penna (criador de As Garotas do Alceu, da revista O Cruzeiro). Uma grande área para guarda-roupas, adereços, complementos e vestiários completava a estrutura que servia a grandes manifestações de moda dessa década que foi, no Brasil, um dos períodos mais férteis e significativos. Projetei, desenhei, cenografei e produzi os shows das grandes feiras de moda da época: Seleção Rhodia Moda na Fenit - Feira Nacional da Indústria Têxtil, de 1963 a 1970.

A maior parte do meu trabalho para o cinema como diretor, cenógrafo ou diretor de arte foi ao lado de duas figuras importantes para a história do cinema nacional, mas quase opostas no temperamento artístico e na visão de mundo: Roberto Santos e Walter Hugo Khouri. Roberto Santos, imortalizado por seu primeiro filme, $O$ Grande Momento, ensinou-me a tratar o cinema com a visão do homem simples e com o olhar do fotógrafo que sabe onde colocar sua visão crítica do mundo, sua câmara. Khouri, por outro lado, deu-me a oportunidade de usar meu prazer e gosto pelos resultados plásticos, a virtude de dar o lugar certo às coisas visuais e cinematográficas que o mundo fornece. Khouri enriqueceu meu trabalho como cenógrafo.

Algo fez da minha relação com Roberto e Khoury uma fraternidade. Com Roberto Santos, participei da realização de A Hora e a Vez de Augusto Matraga, obra de Guimarães Rosa, com quem discutimos longamente o que deveríamos fazer. Nós o encontrávamos no Palácio Itamarati, no Rio de Janeiro, sendo sua mesa aquela que herdara do Barão do Rio Branco. Em seguida, viajamos para os sertões de Minas Gerais e para o quartel de Barbacena, onde Rosa havia servido como médico.

Luiz Carlos Barreto veio a meu escritório na Glória, Rio de Janeiro, e convidou-me para realizar as artes gráficas de Dona Flor e seus dois maridos, um dos mais importantes filmes brasileiros. Nele, fiz de tudo: desenhei a marca 
comunicação \& educação • Ano XII • Número 1 • jan/abr 2007

do filme, fiz os layouts para o pôster, o outdoor, o anúncio e todo o material gráfico. Quando tudo estava pronto, encontrei-me com Bruno Barreto, que dirigia o longa-metragem, e comecei a desenhar o storyboard para a entrada dos títulos impressos sobre as primeiras imagens do filme. Assim, passei a desenhar a abertura do filme.

A Televisão Excelsior é um marco histórico porque dá início à modernidade da televisão brasileira. Para ela, criei o primeiro projeto de identidade institucional a ser usado no país, ou seja, o design, tipologia gráfica e estilo dos cartões identificadores da emissora e dos intervalos, que permitem ao espectador saber a qual emissora está assistindo; o que seria feito em outras emissoras algum tempo depois.

Assumindo a cenografia, pude colocar no ar, sobretudo nos shows dominicais, imagens de artes plásticas, coisa nova na televisão brasileira. Juan Miró como cenografia para programas televisivos, a reconstrução de uma favela no palco, os candelabros da Traviata, às oito da noite no domingo - tudo isso era novidade absoluta em 1960. E pude realizar cenários de shows com recursos teatrais que eu dominava. A televisão era ao vivo e nosso estúdio, o Teatro de Cultura Artística. Criei cenários também para uma série, A História da Medicina, dirigida por Ziembinski.

A partir de então, trabalhei como cenógrafo para os Festivais de MPB da TV Record dirigidos por Manoel Carlos e Nilton Travesso. Projetei um dos cenários da Família Trapo. E foi por causa de um cenário meu para um capítulo semanal com Leonardo Vilar que conheci Lívio Rangan, gerente de promoção da Rhodia, que enriqueceu minha vida nos anos 1960. Com Lívio tive uma parceria de dez anos, fazendo o melhor capítulo da atividade na história da moda brasileira.

Fui para o Rio de Janeiro em 1970, como diretor de arte e cenógrafo da TV Tupi, ainda na Urca. Sabendo que eu estava no Rio, José Bonifácio de Oliveira Sobrinho, o Boni, contratou-me para a TV Globo. Meus primeiros trabalhos foram aberturas e vinhetas de novelas. Mais tarde, a criação de logotipia. Mais tarde ainda, tornei-me diretor de arte do Fantástico, quando era dirigido pelo querido e saudoso Augusto César Vanucci, o profissional que fez a linha de shows da Globo e que formou dentro do padrão Globo de qualidade todos os profissionais que conosco trabalharam: Maurício Sherman, Ronaldo Boscoli, Daniel Filho, Gian Carlo Berardi, Sorensen e muitos outros. Qualquer número musical da linha de shows brilhava mais se passasse pelas mãos de Augusto. Mais tarde, Manoel Carlos assumiu a direção do Fantástico.

\section{OUTROS CARNAVAIS}

Como diretor de arte da Rede Globo de Televisão de 1973 a 1975, recebi um convite para desenhar os carros da Escola de Samba da Portela. Por ser paulista, fui indicado para criar a decoração para o tema: Macunaíma de Mário de Andrade. Foi uma grande experiência! Carros gigantescos atravessariam aquele caudaloso rio de gente, quase de madrugada, com arquibancadas apinhadas para 
Tornei-me o homo faber por excelência • Cyro Del Nero

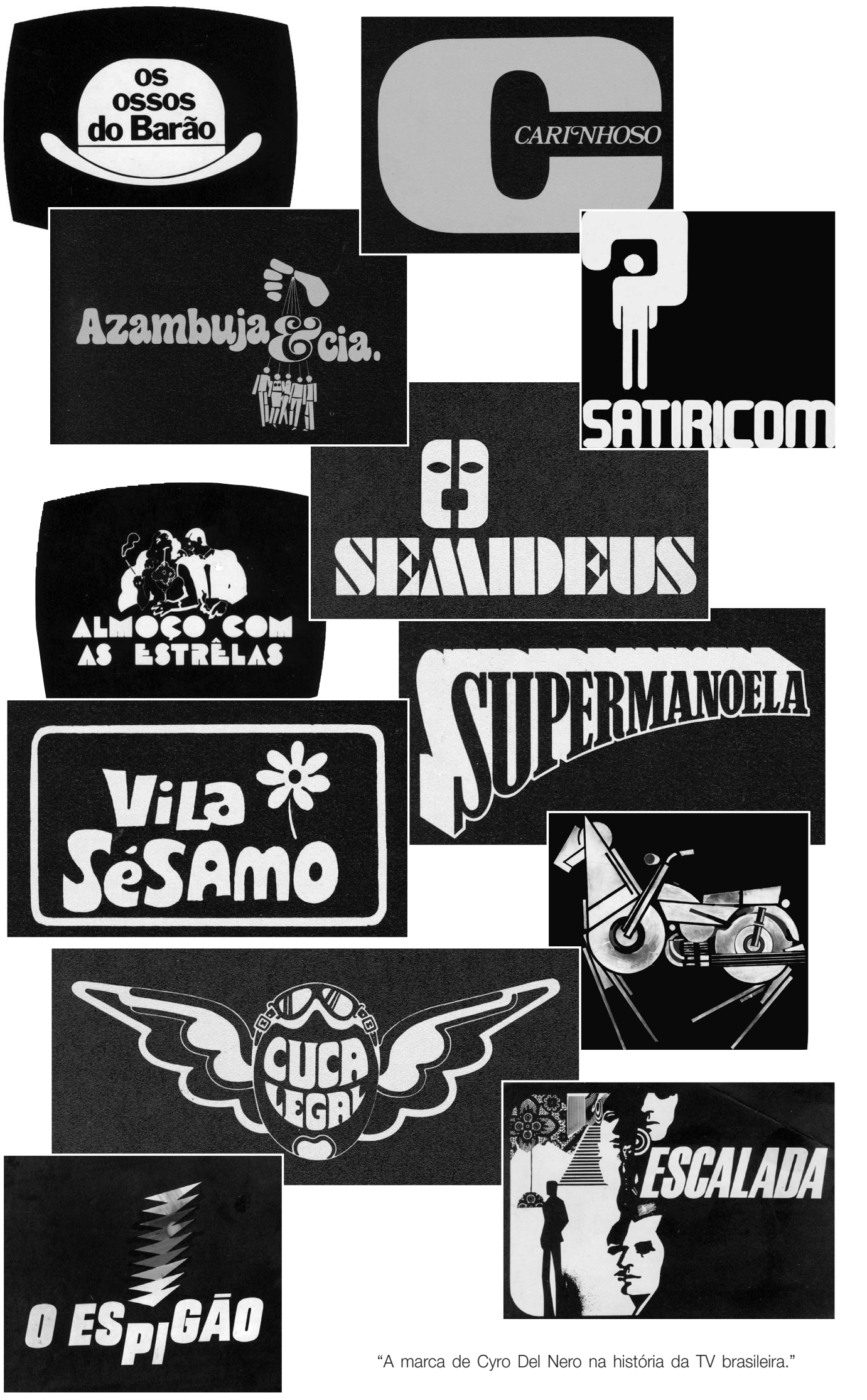


ver passar o cortejo de quatro mil foliões, uma das três maiores escolas de samba do maior Carnaval do mundo. A nota recebida da comissão de julgamento das Escolas de Samba para o quesito cenografia foi 10.

Entre 1960 e 1982, continuei criando logotipos para programas de televisão, bem como marcas para as emissoras Excelsior, Tupi, Globo, Bandeirantes, Brasília e outras. Desenvolvi projetos editoriais para autores como José Lins do Rêgo, Clarice Lispector, Afonso Schmidt, e para outras dezenas de poetas e escritores.

Numa época de grandes novidades, participei de projetos pioneiros: a primeira Discoteca do Brasil, em 1974 - doze anos depois do Electric Circus -, o Papagaio Disco Club de São Paulo; depois também no Rio de Janeiro.

Por duas vezes, fui convidado pelo governo brasileiro para representá-lo em mostras culturais no exterior: Feira de Osaka, no Japão, em 1970, e Museu do Louvre, na França, em 1998. Em 1994, aceitei o convite para ser assessor da diretoria do Centro Cultural São Paulo, da Secretaria da Cultura da Prefeitura do Município de São Paulo, e curador de exposições. Imediatamente, vesti o Centro Cultural com um programa de Comunicação Visual e Signos de Identidade Visual. Dei novo tratamento externo às comunicações e aos outdoors de eventos e espetáculos.

Em parceria com o consulado italiano, a Câmara de Comércio Brasil-Itália, o Instituto de Cultura Italiana e empresas italianas no Brasil, criei e produzi a exposição Imigração italiana.

Gregori Warchavchik foi o primeiro arquiteto que realizou, construiu e ergueu um projeto de arquitetura moderna, com sua Casa Modernista, em São Paulo. Projetei a exposição de sua obra juntamente com os curadores de arquitetura do Centro Cultural São Paulo. Desenhei o roteiro da exposição e a realizei.

\section{OS EVENTOS DA CENOGRAFIA}

Tenho presenciado nestes últimos cinqüenta anos a imensa transformação de uma antiga profissão - a cenografia; uma sempre nova atividade com o mais variado repertório. Hoje, paradas públicas, abertura de jogos olímpicos, shows, desfiles de moda, a renovação de antigos edifícios com novas vocações, a metamorfose de produtos através da cenografia para uma visualização inovadora, a reavaliação de espaços públicos aos quais são agregados propósitos criativos e a revelação de espaços esquecidos por meio de tratamentos cenográficos que lhes emprestam monumentalidade.

Tudo isso é cenografia?

Sim. Não falta oportunidade para cenografar diferentes espaços e temas. Já cenografei palanques políticos e lançamentos de produtos: automóveis, perfumaria, imóveis, moda, obras de arte etc.

Estamos em uma sociedade da performance, na qual nada pode ser imaginado, pensado ou realizado sem que o seja em forma de espetáculo. Portanto, 
a cenografia é uma mídia nova e indispensável. Ela atende à dramaturgia de muitos espaços, e para o cenógrafo todo e qualquer espaço é palco.

São novas vertentes desta arte, embora a cenografia seja antiqüíssima. Podemos datá-la como arte do teatro grego do século VI a.C. Aristóteles conta que quem primeiro a sugeriu foi Sófocles, querendo um apoio dramático para encenação de espaço e tempo. Mas os Xamãs já a usavam antes disso, assim como os atuais pais-de-santo ainda o fazem: a decoração do terreiro ou da sala, os efeitos de luz através do telhado ou velas, a fumaça dos charutos em lugar das atuais maquininhas teatrais de fog, a sonoplastia com tambores e gritos, a indumentária teatral, as máscaras que causam terror. A única diferença é que os meios teatrais procuram causar a catarse e os exercícios teatrais dos pajés querem a terapia e a cura. A cenografia tem servido a ambos.

O último convite que me fizeram e encheu-me de alegria foi criar cenografia para uma coleção de moda atual realizada com a ajuda do talento espontâneo e autóctone de alguns artesãos brasileiros. Bordados com vidrilhos, fuxicos e rendas de bilro vieram colaborar, com sua arte e tradição, para a moda erudita. Eram oito criadores de moda - duas criações de cada um - e um grupo de artesãos que trariam sua contribuição cheia da luz do povo. Para cercar de brilho cenográfico essas obras, deram-me um salão criado para esse fim, no Senac Moda de São Paulo. O espaço tinha uma neutralidade ambiental própria para quem quer expressar um conceito e um conteúdo, uma atmosfera e uma perspectiva, um desenho e uma cor. Em primeiro lugar teria de ser algo impactante, que elevasse o que se ia expor ao nível de uma visão inédita. Decidi

que nada pisaria o solo, nada que fosse modelo ou moda. Dezesseis manequins de vitrine pretos foram suspensos no ar por finos cabos de aço revestidos de plástico (presos por uma alça na cabeça), e giravam lentamente ao sabor da mudança de temperatura ou da corrente de ar. $\mathrm{O}$ que unia o cabo de aço às cabeças era um laço de fita em seda larga de cor negra. $\mathrm{O}$ resultado não foi o de manequins enforcados, mas de figuras acima do bem ou do mal, entretidas apenas com uma existência de beleza. A súbita visão de quem adentrava a exposição causava surpresa pelo espetáculo de movimento, como num baile metafísico, livre da gravidade.

A contribuição da cenografia é a da revelação e do enriquecimento. Como no caso dos manequins suspensos, ela tira o que pode pesar na existência das coisas, dá forma e faz desabrochar a intenção dos eventos.

Hoje é impossível não cenografar aquilo a que se quer dar uma existência mais significativa. Antigamente significava decorar, enfeitar. Agora, a intenção é a de acentuar conceitos.

\section{A EXPERIÊNCIA COM A EDUCAÇÃO}

Foi no Centro Cultural São Paulo que pude iniciar a realização do sonho de ensinar, através de um pôster que dizia: História da Cenografia, 10 aulas, 3 aulas por semana. Fui convidado a montar, dirigir e dar aulas para um Curso 
de Artes Plásticas do Teatro, o qual eu deveria propor e organizar, no Sesc - Serviço Social do Comércio. Montei esse curso convidando professores para ensinar História do Estilo, Perspectiva, História do Edifício Teatral e outras matérias. Dei aulas de História do Teatro e História da Cenografia. Durante seis meses, formamos um grupo de dezoito alunos que, nas últimas semanas do curso, criaram projetos para uma exposição sobre diversos textos teatrais, sendo algumas concepções de alto interesse e de alta qualidade de representação e realização.

Em 1998, como um especialista, recebi o honroso convite para ser professor da Escola de Comunicações e Artes (Departamento de Artes Cênicas) da Universidade de São Paulo; e, depois, prestei concurso e me tornei professor titular de Cenografia e Indumentária Teatral. Encarei o convite como um alargamento do prazer de ensinar e uma honra pela convivência com os companheiros universitários.

Comecei a ensinar aos 60 anos de idade. Aprendi muito com meus alunos, sobretudo a ter a dimensão e consciência do que eu já sabia. Até então, via meu ofício como se estivesse em um trem observando a paisagem passar aos pedaços pela janela. Quando comecei a ensinar enxerguei a paisagem inteira, sentado em cima do trem. Aprendi muito sistematizando a história da cenografia, descobrindo como é antigo e humilde meu ofício a serviço dos poetas. Tomei consciência de como a cenografia é anterior ao teatro, de como flui nos ofícios

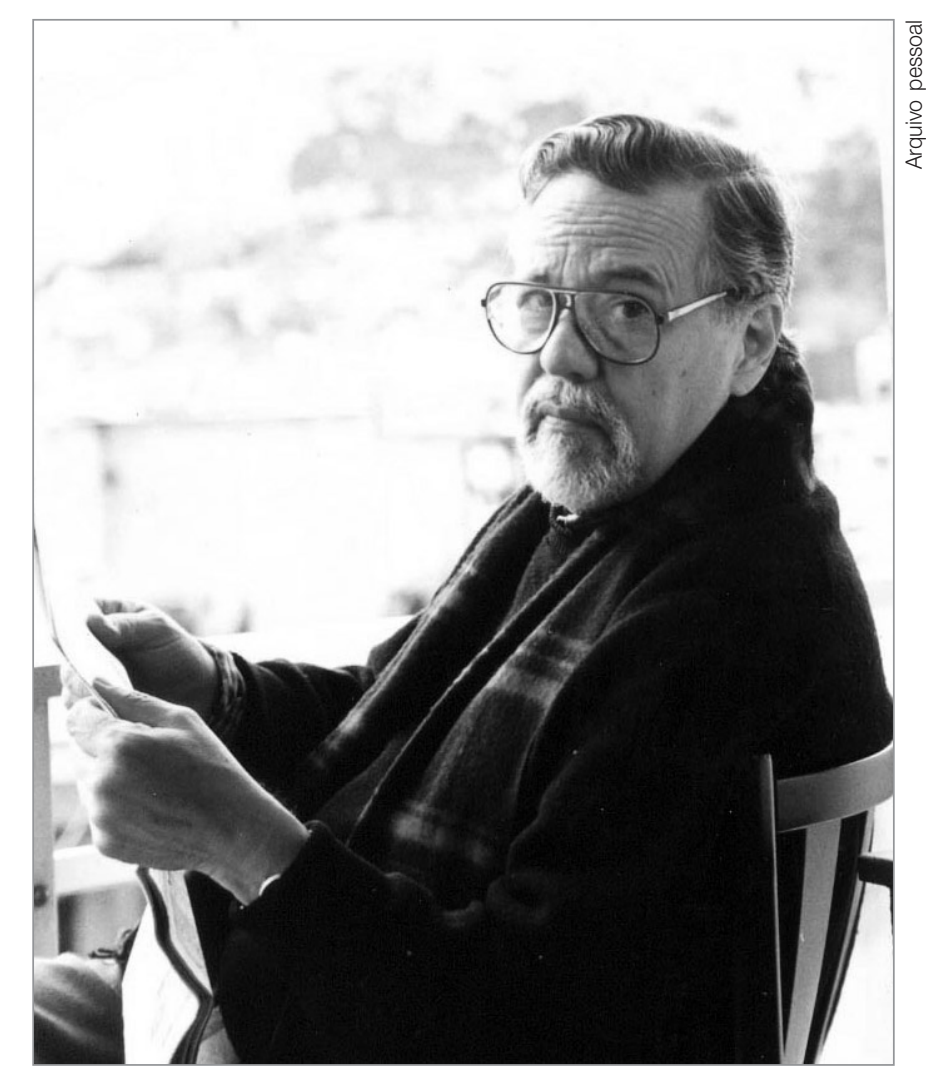

Cyro Del Nero: um faz-tudo que ama tudo o que faz. 
mais humildes e se expressa, mas se expressa em altos níveis de grandeza: há cenografia em tudo, como em tudo há teatro. Ensinar foi abrir-me e receber dos alunos novas perguntas e, também, as melhores perguntas - aquelas para as quais não temos resposta.

Apesar de me orgulhar por ser de uma geração autodidata, se tivesse de começar tudo de novo entraria para uma escola. Mas onde não houver escola, o melhor é enturmar-se; cercar-se de amigos que amem determinada atividade, objeto ou linguagem e queiram se dedicar a ela - foi isso que fiz. Criar uma família, como no teatro: diretor, ator, cenógrafo, iluminador, aderecista, figurinista etc. Se não houver escola disponível onde estiverem, comecem como amadores e se desenvolvam em direção ao profissionalismo. Amador é um nome nascido da palavra amor: não há nada de menor em ser amador. Muitas vezes o entusiasmo e a energia do amador não sobrevivem no profissional.

Esta é a história que um faz-tudo tem a contar.

Resumo: Neste depoimento, Cyro Del Nero conta sobre seus mais de 56 anos atuando como cenógrafo nas diferentes áreas das artes e espetáculos, e nos meios de comunicação e entretenimento. Traz em seu currículo trabalhos para o teatro realizados na Grécia e na Alemanha. Apresentou exposições na Quadrienal de Cenografia de Praga, exTchecoslováquia. No Brasil, produziu para o TBC, fez exposições e ganhou diversos prêmios; foi o criador e realizador das instalações do Pavilhão Brasileiro na EXPO 70 - em Osaka, no Japão. Trabalhou para o cinema e para a televisão, transformando-se no que ele mesmo chama um homo faber por excelência, que, entre todas suas artes, se dedicou ainda à docência.

Palavras-chave: cenografia, artes e espetáculos, moda, cinema, televisão.
Abstract: In his testimony Cyro Del Nero tells of his more than 56 years acting as set designer in distinct areas of arts and spectacles, and media and entertainment. His curriculum shows works for theater in Greece and Germany, as well expositions in the Prague Quadrennial of Scenography. He was the creator and performer of the Brazilian Pavilion EXPO 70 - in Osaka, Japan. In Brazil, he produced for TBC, made expositions and was awarded several times. Worked for cinema and television, becoming what he calls a homo faber par excellence, who, among all those activities, has also dedicated to teaching.

Keywords: scenography, arts and spectacles, fashion, cinema, television. 